
$\$$ Research Square
Preprints are preliminary reports that have not undergone peer review.
They should not be considered conclusive, used to inform clinical practice, or referenced by the media as validated information.

\title{
Nonlinear vibration analysis of the nanobeams subjected to magneto-electro-thermo loading based on a novel HSDT
}

Reza Mohammadi ( $\sim$ mohammadireza456@yahoo.com)

Tarbiat Modares University

\section{Research Article}

Keywords: Magneto-electro-thermo-elastic nanobeams, Novel HSDT, Nonlocal elasticity theory, Size effect, Perturbation technique

Posted Date: April 14th, 2021

DOl: https://doi.org/10.21203/rs.3.rs-364673/v1

License: (c) (i) This work is licensed under a Creative Commons Attribution 4.0 International License.

Read Full License 


\section{Abstract}

In this paper, the nonlinear vibration analysis of the nanobeams subjected to magneto-electro-thermo loading based on a novel HSDT is studied. Nonlocal elasticity theory is applied to consider the small scale effect. The nonlinear equations of motion are derived using Hamilton's principle. First, a Galerkinbased numerical technique is applied to reduce the nonlinear governing equation into a set of Duffingtype time-dependent differential equations. Afterward, the analytical solutions are derived based on the method of multiple scales (MMS) and perturbation technique. All of the mechanical properties of the beam are temperature dependent. The impacts of the several variables are investigated on the nonlinear frequency ratio of the nanobeams. The results illustrate that when maximum deflection is smaller/ greater than 0.2 , its impact on the nonlinear frequency ratio will decrease/increase.

\section{Full Text}

This preprint is available for download as a PDF.

\section{Figures}

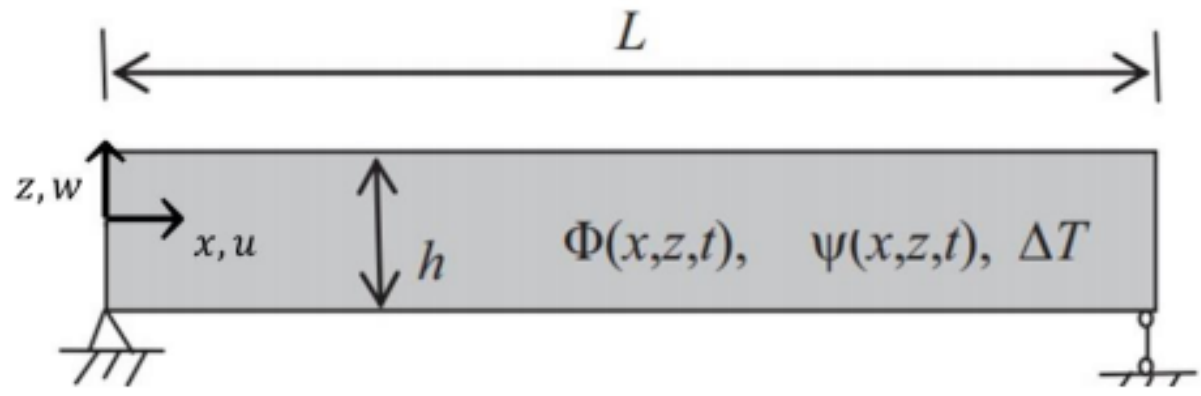

\section{Figure 1}

Nanobeam with geometrical properties 


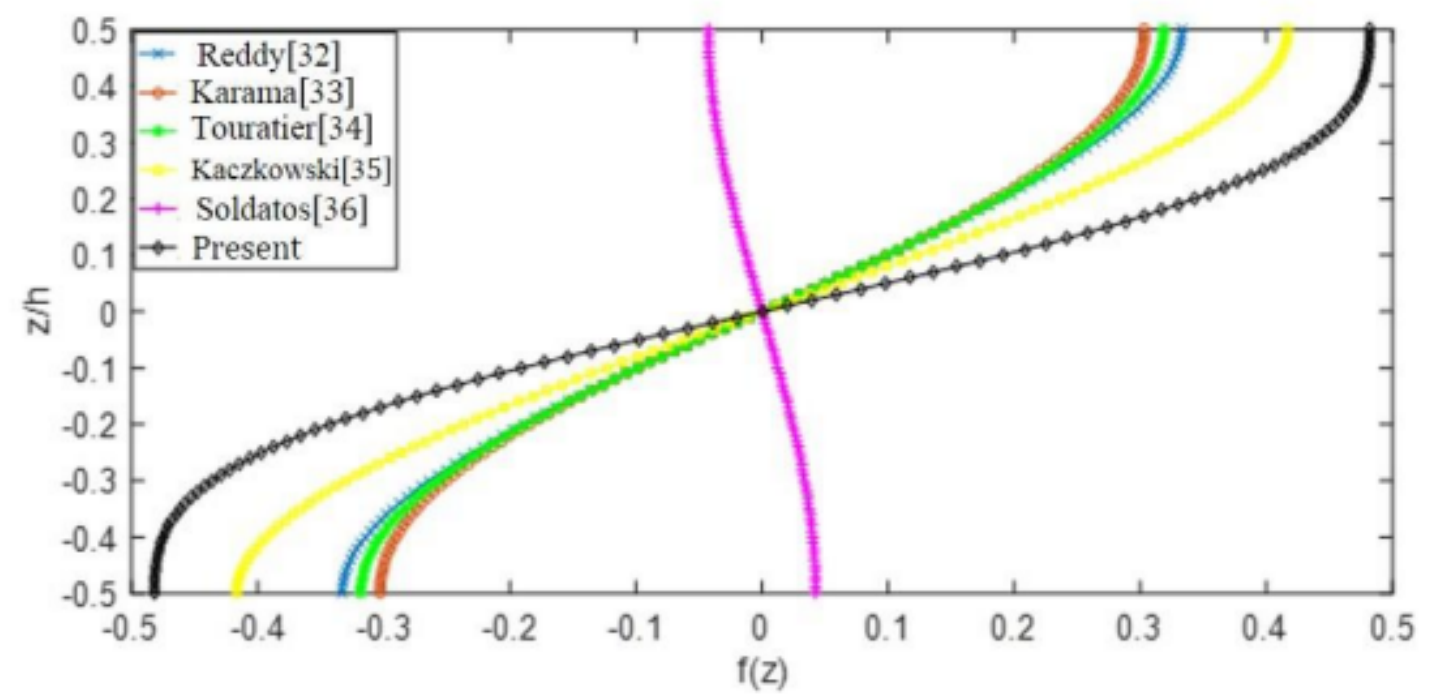

Figure 2

The variation of the shape function through the thickness for several theories

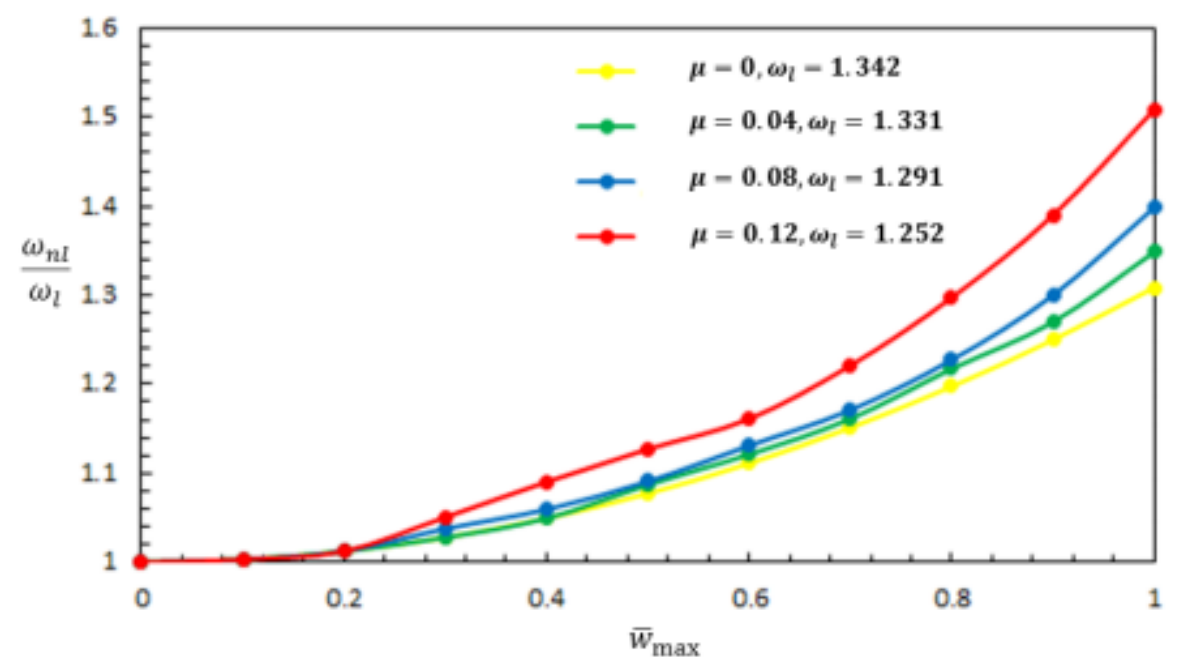

Figure 3

The impacts of size effect parameter on the nonlinear frequency ratio 


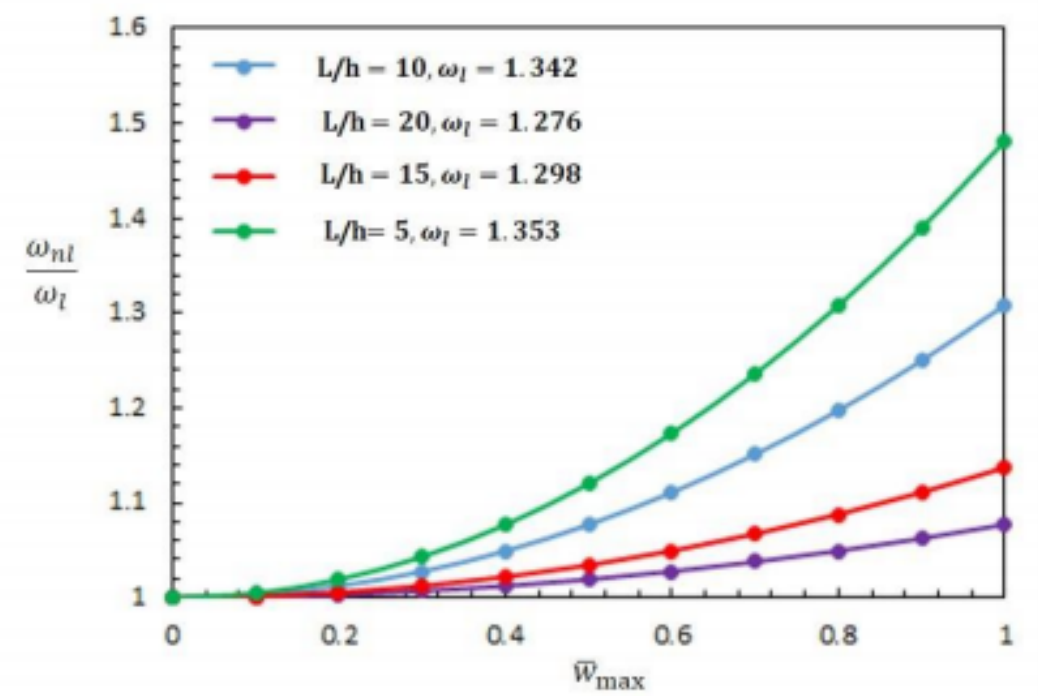

\section{Figure 4}

The impacts of length-to-thickness ratio on the nonlinear frequency ratio

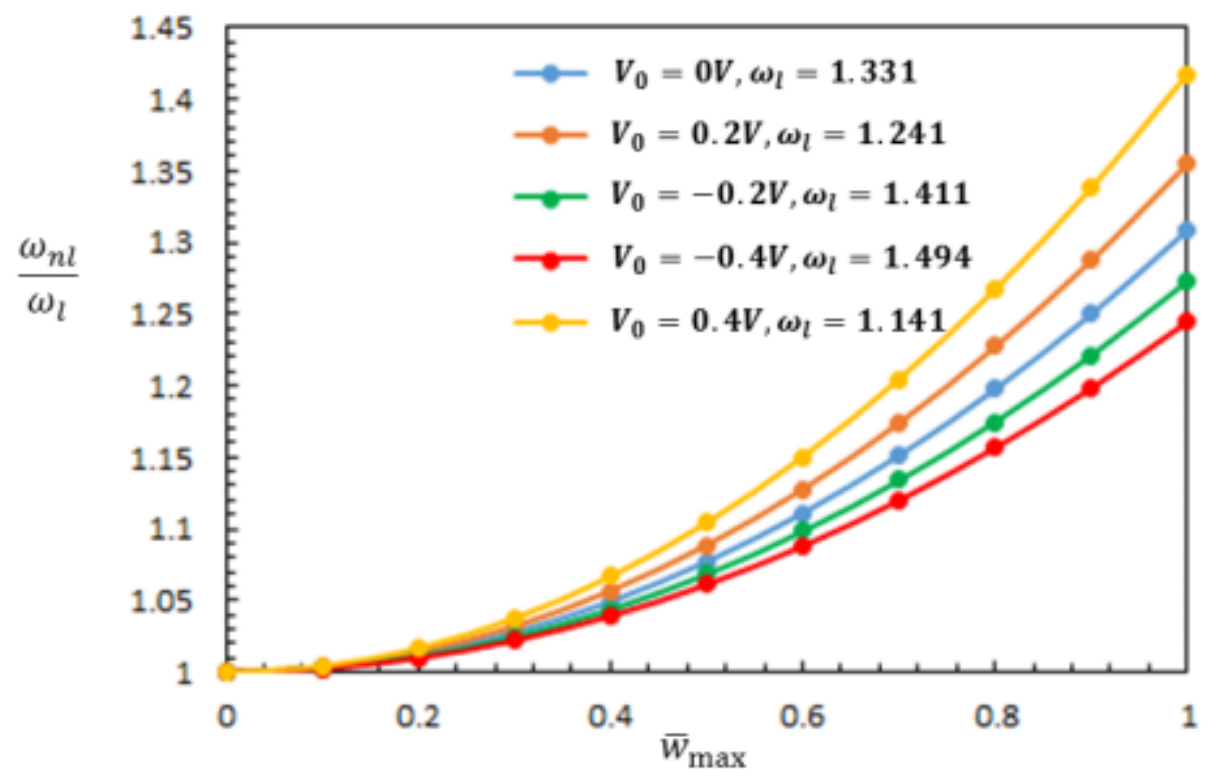

Figure 5

The impacts of external electric potential on the nonlinear frequency ratio 


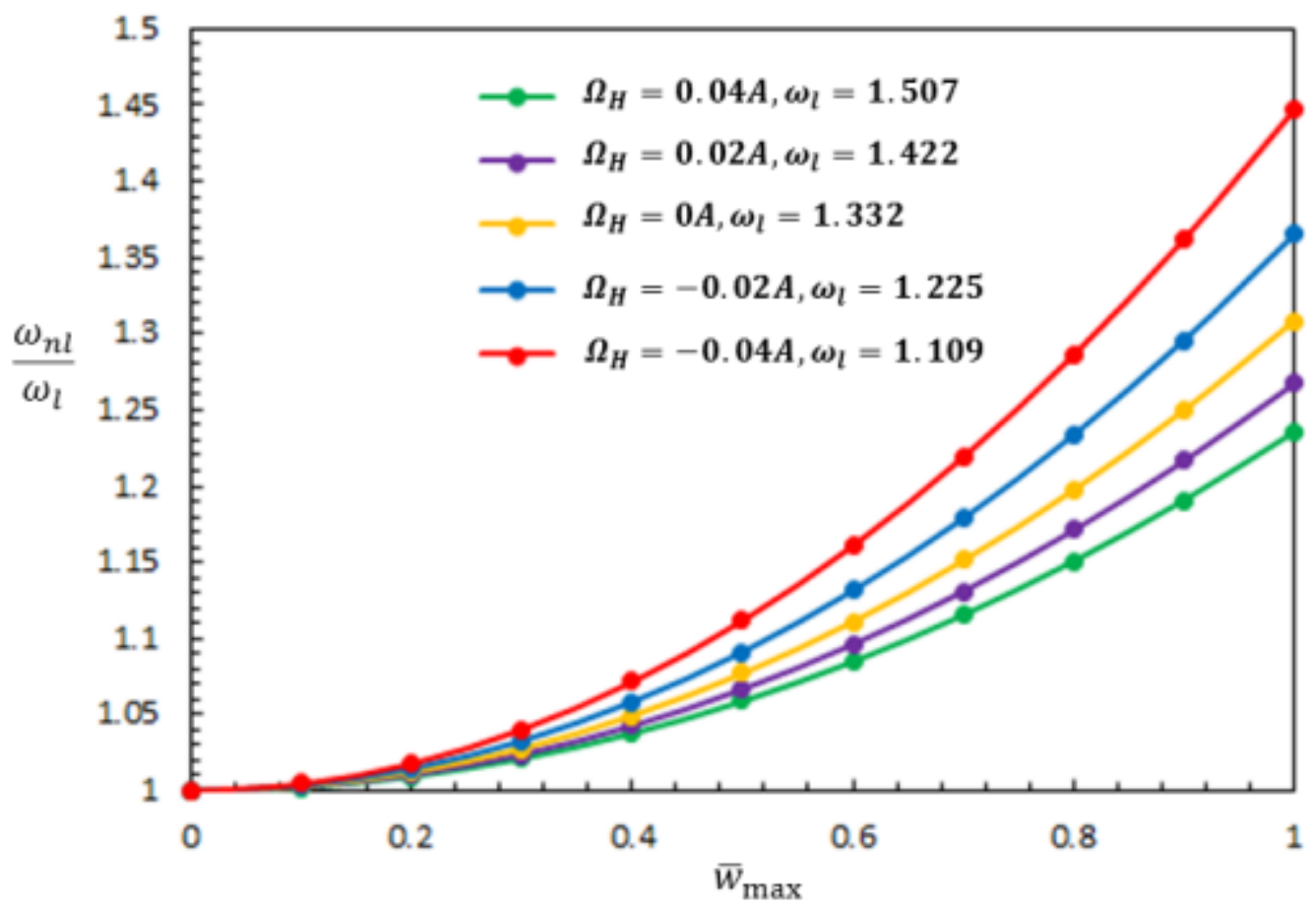

Figure 6

The impacts of external magnetic potential on the nonlinear frequency ratio 